\title{
Aortic arch calcification in hypertensive patients with chronic kidney disease
}

Claudia Floriana SUCIU ${ }^{1,2}$, Andreea VARGA ${ }^{1,3}$, Corneliu Florin BUICU ${ }^{4}$, Valeria HERDEA ${ }^{2}$, Toader Septimiu VOIDAZAN ${ }^{5}$, Ioan TILEA ${ }^{1,3}$

${ }^{1}$ Family Medicine Discipline, Department M3 Clinical Sciences - Internal Medicine, Faculty of Medicine, University of Medicine, Pharmacy, Sciences and Technology, Targu Mures, Romania ${ }^{2}$ Doctoral School, University of Medicine, Pharmacy, Sciences and Technology, Targu Mures, Romania ${ }^{3}$ Department of Cardiology - Internal Medicine II Clinic, Emergency Clinical County Hospital, Targu Mures, Romania

${ }^{4}$ Public Health and Management Discipline, Department M2 Functional and Complementary Sciences, Faculty of Medicine, University of Medicine, Pharmacy, Sciences and Technology, Targu Mures, Romania

${ }^{5}$ Epidemiology Discipline, Department M2 Functional and Complementary Sciences, Faculty of Medicine, University of Medicine, Pharmacy, Sciences and Technology, Targu Mures, Romania

\begin{abstract}
Introduction. Vascular calcification is an independent risk factor related to cardiovascular mortality in CKD patients. Advanced aortic arch calcification assessed by semi-quantitative estimation on posteroanterior chest X-ray is a strong independent predictor of cardiovascular events in CKD and non-CKD patients, beyond traditional risk factors. An association between aortic arch calcification and hypertension has been previously reported however, the presence of CKD has not recorded in most studies. The aim of our study was to identify risk factors related to aortic arch calcification in hypertensive $C K D$ patients.

Material and method. A retrospective observational study on 63 hypertensive patients with CKD stages $G 2$ to G4, that had a posteroanterior chest $X$ ray available was conducted. The study population was divided into 2 groups according to presence or absence of aortic arch calcification on chest X-rays. Chest X-ray identified 43 patients with aortic arch calcification. Laboratory data were recorded for every individual simultaneously with the following comorbidities: coronary artery disease, carotid stenosis, hypertensive cardiopathy, lower extremity arterial disease.

Outcomes. Groups were homogenous regarding gender distribution, creatinine levels and diabetes mellitus prevalence. We found no a statistically significant difference regarding comorbidities between the two groups. Lactate dehydrogenase and alkaline phosphatase had a statistically significant association with aortic arch calcification ( $p=0.043, p=0.006$ respectively).

Conclusions. Increased alkaline phosphatase remains an important risk factor for aortic arch calcification even in patients with less advanced CKD. Lactate dehydrogenase is yet to be validated as a marker for aortic arch calcification in CKD patient, however, our study reports a statistically significant association between lactate dehydrogenase and aortic arch calcification in patients with CKD.
\end{abstract}

Keywords: aortic arch calcification, chronic kidney disease, hypertension 


\section{INTRODUCTION}

Cardiovascular (CV) disease is a prevalent cause of death in patients with chronic kidney disease (CKD) [1]. An independent risk factor related to cardiovascular mortality in CKD patients is represented by vascular calcification [2]. In a study conducted in more than 139,000 patients, Iribarren et al. reported that aortic arch calcification $(A A C)$, identified by conventional chest $X$-ray radiography, can be an indicator atherosclerotic disease extension, and a predictor of $\mathrm{CV}$ ischemic events [3]. Advanced AAC calcification (grade 2 and 3) assessed by semi-quantitative estimation of AAC on posteroanterior chest $\mathrm{X}$-ray examination, is a strong independent predictor of CV events in CKD and non-CKD patients, beyond traditional risk factors $[4,5]$.

The pathomechanisms responsible for aortic calcification in CKD patients involves non-traditional risk factors as well. Disorders of the calcium and phosphorus metabolism with calcium excess, phosphate retention, high doses of active vitamin D therapy, and also bone metabolism errors are additional contributors to vascular calcification in CKD patients $[2,6]$.

Arterial calcification occurs in two distinct layers of the arterial wall, intima and media, both being associated with $\mathrm{CV}$ morbidity and mortality in CKD $[6,7]$. Intimal calcification is also known as atherosclerotic calcification is commonly found in large arteries, such as the aorta, and is associated with traditional $\mathrm{CV}$ risk factors like ageing, hypertension, dyslipidaemia, and diabetes mellitus [8]. Calcific atherosclerosis has the same distribution as atherosclerosis. Calcified atherosclerotic lesions are organized in plaques with a patchy distribution in the proximity of lipid depositions that enlarge the arterial wall leading to lumen narrowing, and plaque instability $[6,9,10]$.

Medial calcification or Mönckeberg's arteriosclerosis is characterized by metaplastic bone formation, with linear, sheet-like calcification in the smooth muscle layer of the arterial wall in small and medium-sized arteries in the absence of atheroma, without lumen narrowing; it increases the arterial stiffness, pulse pressure, and is correlated to left ventricular hypertrophy $[6,11-13]$. Media calcification in CKD patients is not influenced by dyslipidaemia. Furthermore, in some arterial beds, the changes in calcium and phosphate disorders are not responsible for calcification; however, local inflammation might be an important contributor [6].

Clinical manifestations of arterial calcification depend on vascular wall localization and perfused tissue. Extensive calcification of the ascending aorta or aortic arch that can be completely or near completely circumferential is a possible consequence of medial and intimal calcification [14]. Even though two independent processes influence aortic calcification, these separate events have considerable overlap in advanced atherosclerotic disease in CKD patients [6]. With decreasing kidney function, the prevalence of vascular calcification increases, and arterial calcification occurs years earlier in CKD individuals than in the general population [15]. Additionally, a more advanced arterial calcification has been reported in patients with end-stage CKD compared to coronary artery disease (CAD) patients [16].

Hypertension is recognized as one of the traditional risk factors for atherosclerotic disease. A blood pressure (BP) dysregulation with constant increased values leads to a progressive hypertensive nephropathy. Early diagnosis and treatment of high BP reduces hypertension mediated organ damage (HMOD), particularly CKD. Consecutively mild kidney damage in non-hypertensive patients, will determine raised $\mathrm{BP}$ as a consequence of various mechanisms such as water retention, activation of the renin-angiotensin-aldosterone system and increased reactivity of the sympathetic system [17]. An association between AAC and hypertension has been previously reported; however, the presence of CKD has not recorded in most studies $[18,19]$.

Calcification of the aorta can easily be identified on conventional posteroanterior chest X-ray. A reliable grading system for AAC that accurately reflects the extend of aortic calcification is available [20]. AAC extent is classified into four grades: grade 0 , absence of calcification; grade 1 , a single thin calcification region or small spot; grade 2 , one or more broad calcification areas; grade 3 , circumferential calcification [5].

The aim of our study was to identify risk factors related to aortic arch calcification in hypertensive CKD patients.

\section{MATERIAL AND METHODS}

A retrospective observational study was conducted in an university-based hospital, between April 2018 to June 2019. Data were collected using available electronic data base files. Demographic and medical data, including age, gender, BMI and comorbid conditions were assessed.

Diagnosis of hypertension was reassessed according to 2018 ESC/ESH Arterial Hypertension (Management of) Guidelines [21]. 
TABLE 1. Gender (male) * Aortic calcification on chest X-ray

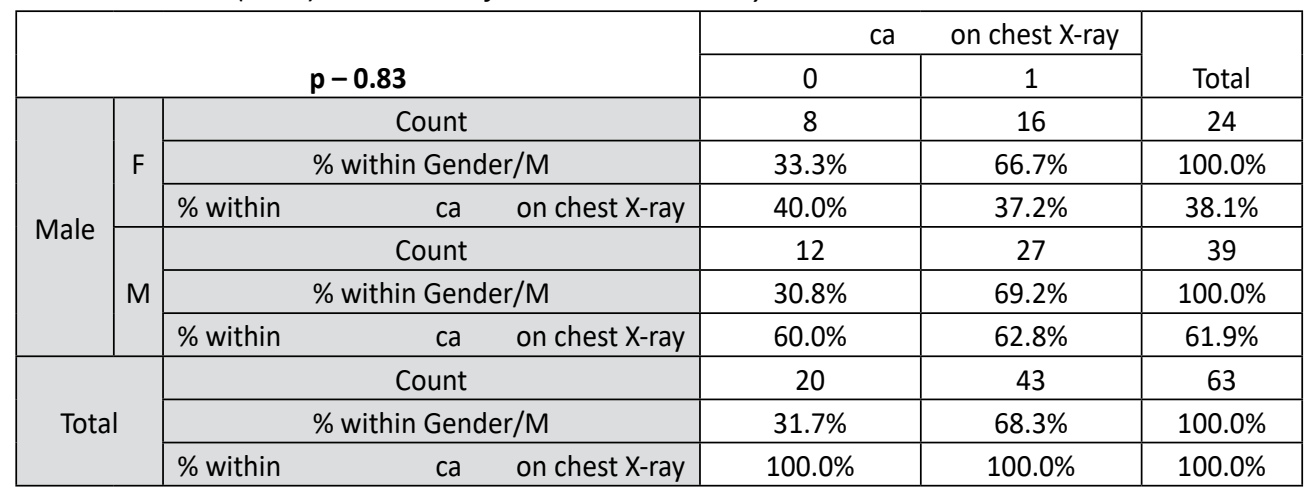

*test Student

CKD diagnosis used the Kidney Disease Improving Global Outcomes (KDIGO) 2012 Clinical Practice Guideline for the Evaluation and Management of Chronic Kidney Disease, based on GFR (glomerular filtration rate) category criteria [22].

Patients were classified in GFR categories as: G2 with GFR values of $60-89 \mathrm{ml} / \mathrm{min} / 1.73 \mathrm{~m}^{2}$, G3a with GFR values of $45-59 \mathrm{ml} / \mathrm{min} / 1.73 \mathrm{~m}^{2}$, G3b with GFR values of $30-44 \mathrm{ml} / \mathrm{min} / 1.73 \mathrm{~m}^{2}$ and G4 with GFR values of $15-29 \mathrm{ml} / \mathrm{min} / 1.73 \mathrm{~m}^{2}$. Individuals with GFR categories G3a-G5 had a decreased GFR duration of more than three months.

A number of 63 hypertensive patients with CKD had a posteroanterior chest $\mathrm{X}$-ray available.

The study population was divided into two groups related to the presence or absence of AAC on chest X-rays. The AAC was identified in 43 patients. Calcification of the aortic arch was assessed using the scale described above [5]. All 43 patients presented AAC grade 2 to 3 .

Presence of CAD, carotid stenosis, hypertensive cardiopathy and lower extremity arterial disease were recorded in both groups.

Lab tests were also collected: erythrocyte sedimentation rate (ESR), fibrinogen, iron, total serum calcium, creatinine, urea, total cholesterol, triglycerides, alkaline phosphatase (AP), lactate dehydrogenase (LDH), alanine transaminase (ALT), aspartate transaminase (AST), gamma-glutamyl transferase (GGT), total bilirubin, uric acid.

Statistical analysis was performed using the GraphPad Prim 3.1 software (GraphPad Software Inc., San Diego, USA) and SPSS 22.0 (IMB Corp. Released 2013. IMB SPSS Statistics for Windows, Version 22.0. Armonk, NY: IMB Corp.). Continuous variables are presented as mean \pm standard deviation (SD), while categorical variables are expressed as numbers. Student's $t$ test was used for inferential statistics for parametric data and the Mann-Whitney test for non-parametric data. A p value of $<0.05$ was considered statistically significant.

\section{RESULTS}

A total of 63 patients (39 men and 24 women) with CKD stages $\mathrm{G} 2$ to $\mathrm{G} 4$ were included. We did not identified in our study patients in G0, G1 or G5 CKD stages. Patients were divided according to the presence of AAC into two groups: group 1 with $A A C$ and group 2 without AAC.

Group 1 consisted of 43 patients (16 women, 27 male), mean age $75.93 \pm 7.156$ years.

Group 2 included 20 patients (8 women, 12 male), mean age $67.3 \pm 3.935$ years. With respect to gender distribution, our two groups were homogenous, without a statistically significant difference between male participants ( $p=0.83)$, as shown in table 1.

There was no significant statistical difference between group 1 and group 2 regarding ESR and serum levels of: fibrinogen, iron, total calcium, creatinine, triglyceride, total bilirubin, AST, ALT, GGT and uric acid.

Age was statistically significant different between patients with AAC and those without AAC $(p=0.001)$ as patients in group 1 were older than patients in group 2.

Furthermore, patients from group 1 had higher urea levels $(p=0.014)$, alkaline phosphatase levels $(p=0.006)$, lactate dehydrogenase levels $(p=$ $0.043)$, total cholesterol values $(p=0.044)$ and $a$ more advanced CKD with lower GFR ( $p=0.002$ ).

In terms of comorbidities, no statistically significant difference was found between the two groups regarding the presence of CAD $(0=0.8)$, carotid artery stenosis $(p=0.08)$ hypertensive cardiopathy $(p=0.42)$, lower extremity artery disease $(p=0.55)$. Furthermore, no difference regarding the prevalence of diabetes mellitus between the two groups was identified ( $p=0.54)$.

We computed the study patients to different stages of CKD, resulting: 12 patients in G2 stage, G3a 30 patients, G3b 13 patients and G4 four pa- 
TABLE 2. Statistical analysis in the two groups: demographic data and lab test

\begin{tabular}{|c|c|c|c|}
\hline $\begin{array}{l}\text { Variables } \\
\text { mean } \pm S D\end{array}$ & $\begin{array}{c}\text { Aortic calcification on } \\
\text { chest X-ray (yes) } \\
\text { (n-43, 68.25\%) }\end{array}$ & $\begin{array}{c}\text { Aortic calcification on } \\
\text { chest X-ray (no) } \\
\text { (n-20, 31.75\%) }\end{array}$ & $p$ value \\
\hline Age (years) & $75.93 \pm 7.15$ & $67.30 \pm 3.93$ & $0.001 *$ \\
\hline Male, no (\%) & $27(62.8)$ & $12(60.0)$ & \multirow[t]{2}{*}{$0.83^{* *}$} \\
\hline Female, no (\%) & $16(37.2)$ & $8(40.0)$ & \\
\hline BMI $\left(\mathrm{kg} / \mathrm{m}^{2}\right)$ & $28.13 \pm 4.70$ & $20.20 \pm 4.57$ & $0.404^{*}$ \\
\hline $\begin{array}{l}\text { ESR median (min-max) } \\
\text { (NV: 5-17 mm/h) }\end{array}$ & $22(4-69)$ & $86.1(14.7-355.9)$ & $0.08 * * *$ \\
\hline $\begin{array}{c}\text { Fibrinogen } \\
\text { (NV:1.5-4.0 g/l) }\end{array}$ & $4.58 \pm 1.88$ & $4.03 \pm 0.69$ & $0.71 * * *$ \\
\hline $\begin{array}{c}\text { Iron } \\
\text { (NV: } 9.0-30.4 \mu \mathrm{mol} / \mathrm{l})\end{array}$ & $12.72 \pm 5.13$ & $12.76 \pm 6.50$ & $0.973^{*}$ \\
\hline $\begin{array}{c}\text { Total Calcium } \\
\text { (NV: } 2.15-2.57 \mathrm{mmol} / \mathrm{l}) \\
\end{array}$ & $2.28 \pm 0.13$ & $2.13 \pm 0.23$ & $0.67^{*}$ \\
\hline $\begin{array}{c}\text { Creatinine } \\
\text { (NV: } 0.5-1 \mathrm{mg} / \mathrm{dl})\end{array}$ & $1.49 \pm 0.39$ & $1.32 \pm 0.52$ & $0.16^{*}$ \\
\hline GFR (CKD-EPI formula) & $43.09 \pm 12.24$ & $55.2 \pm 13.18$ & $0.002^{*}$ \\
\hline $\begin{array}{c}\text { Urea } \\
\text { (NV: } 2.49-7.74 \mathrm{mmol} / \mathrm{l})\end{array}$ & $15.78 \pm 12.53$ & $9.82 \pm 2.84$ & $0.014 * * *$ \\
\hline $\begin{array}{c}\text { Total cholesterol } \\
\text { (NV: } 2.8-5.2 \mathrm{mmol} / \mathrm{l})\end{array}$ & $4.41 \pm 1.37$ & $3.37 \pm 0.83$ & $0.044^{*}$ \\
\hline $\begin{array}{c}\text { Triglyceride } \\
\text { (NV: } 0.55-1.90 \mathrm{mmol} / \mathrm{l})\end{array}$ & $1.41 \pm 0.67$ & $1.48 \pm 0.81$ & $0.586 * * *$ \\
\hline $\begin{array}{c}\text { Total bilirubin } \\
\text { (NV: } 0.3-1.2 \mathrm{mg} / \mathrm{dl})\end{array}$ & $0.90 \pm 0.55$ & $0.76 \pm 0.39$ & $0.421 * * *$ \\
\hline $\begin{array}{c}\text { AST } \\
\text { (NV: } 5.0-45 \mathrm{U} / \mathrm{I})\end{array}$ & $23.28 \pm 9.65$ & $25.49 \pm 12.72$ & $0.564 * * *$ \\
\hline $\begin{array}{c}\text { ALT } \\
\text { (NV: } 5.0-45 \mathrm{U} / \mathrm{I}) \\
\end{array}$ & $21.21 \pm 11.04$ & $26.83 \pm 17.48$ & $0.268 * * *$ \\
\hline $\begin{array}{c}\text { GGT } \\
\text { (NV: } 7-32 \mathrm{U} / \mathrm{I})\end{array}$ & $51.59 \pm 43.45$ & $34.47 \pm 16.93$ & $0.280 * * *$ \\
\hline $\begin{array}{l}\text { Alkaline phosphatase } \\
\text { (NV: } 100-300 \mathrm{U} / \mathrm{I})\end{array}$ & $265.8 \pm 96.79$ & $210.1 \pm 106.2$ & $0.006 * * *$ \\
\hline $\begin{array}{l}\text { Lactat dehidrogenase } \\
\text { (NV: } 240-480 \mathrm{U} / \mathrm{I})\end{array}$ & $356.8 \pm 138.4$ & $300.00 \pm 100.3$ & $0.043 * * *$ \\
\hline $\begin{array}{c}\text { Uric acid } \\
\text { (NV: } 200-400 \mathrm{U} / \mathrm{I})\end{array}$ & $383.77 \pm 124.12$ & $377.37 \pm 88.10$ & $0.841^{*}$ \\
\hline
\end{tabular}

\section{*Student $t$ test, ${ }^{* *}$ chi ${ }^{2}$ test, ${ }^{* * *}$ Mann Whitney test}

Abbreviations: ALT - alanine transaminase; AST - aspartat transaminase; BMI - body mass index; ESR - erythrocyte sedimentation rate; GGT - gamma-glutamyl transferase, NV - normal values

TABLE 3. Diabetes mellitus prevalence in the two groups (Student's $t$ test)

\begin{tabular}{|c|c|c|c|c|c|c|c|}
\hline \multirow{2}{*}{\multicolumn{5}{|c|}{$p-0.54$}} & \multirow[b]{2}{*}{0} & on chest X-ray & \multirow[b]{2}{*}{ Total } \\
\hline & & & & & & 1 & \\
\hline \multirow{6}{*}{$\begin{array}{l}\text { Diabetes } \\
\text { mellitus }\end{array}$} & \multirow{3}{*}{ no } & & Cour & & 10 & 25 & 35 \\
\hline & & & diabe & mellitus & $28.6 \%$ & $71.4 \%$ & $100.0 \%$ \\
\hline & & $\%$ within & ? $\mathrm{ca}$ & on chest X-ray & $50.0 \%$ & $58.1 \%$ & $55.6 \%$ \\
\hline & \multirow{3}{*}{ yes } & & Cour & & 10 & 18 & 28 \\
\hline & & & diabe & mellitus & $35.7 \%$ & $64.3 \%$ & $100.0 \%$ \\
\hline & & $\%$ within & 回ca & on chest X-ray & $50.0 \%$ & $41.9 \%$ & $44.4 \%$ \\
\hline \multirow{3}{*}{\multicolumn{2}{|c|}{ Total }} & & Cour & & 20 & 43 & 63 \\
\hline & & \multicolumn{3}{|c|}{$\%$ within diabetes mellitus } & $31.7 \%$ & $68.3 \%$ & $100.0 \%$ \\
\hline & & $\%$ within & ? $\mathrm{ca}$ & on chest X-ray & $100.0 \%$ & $100.0 \%$ & $100.0 \%$ \\
\hline
\end{tabular}


tients. No statistically significant difference was noted when comparing the different studied variables in the same CKD stage between the two groups.

\section{DISCUSSIONS}

Aortic arch calcification in CKD patients is a common finding [23]. In individuals with advanced kidney disease, AAC is considered a risk factor for cardiovascular morbidity and mortality [24]. The pathomechanisms of AAC is multifactorial and in CKD patients it is related not only to traditional atherosclerotic risk factors but also to non-traditional risk factors such as the disorders in calcium and phosphorus metabolism. Higher phosphate serum levels may lead to the formation of calcified atherosclerotic plaques by inducing an osteochondrogenic phenotype in vascular smooth muscle cells and by enhancing of the endothelial dysfunction $[25,26]$. The induction of osteochondrogenic phenotype in smooth muscle cells is not dependent on phosphate alone, but on calcium-phosphate nanocrystals as well [27]. Although patients with CKD generally present normal serum calcium levels, it is assumed that total body calcium levels are increased [28]. Furthermore, hypercalcemia enhances apoptosis and matrix vesicle, events responsible for vascular calcification [25]. Phosphate levels were not determined in our study and we found no statistically significant difference between the total serum calcium level between the two groups. On the other hand, total calcium balance was not evaluated.

Serum uric acid is an independent risk factor for CV disease [29]. A relation between increased uric acid levels and AAC was not found in our study which is consistent with previously reported data [30]. However, uric acid has been reported as a surrogate marker for the presence of subclinical coronary atherosclerosis and coronary artery calcification [31].

Lactate dehydrogenase are elevated in advanced CKD and are corelated with urea levels [32]. In our study we found a correlation between $A A C$ and increased lactate dehydrogenase and urea levels in CKD stages G2 to G4 and hyperten- sive patients. An association between lactate dehydrogenase and AAC in CKD and non-CKD patients has not been reported yet.

Elevated serum alkaline phosphatase is a validated marker for the development and progression of arterial calcification in patient with advanced kidney disease [33]. CKD patients have increased levels of alkaline phosphatase as a consequence of disturbance on bone metabolism. Additionally, increased alkaline phosphatase is associated with coronary artery calcification and mortality in maintenance hemodialysis patients [33]. Likewise, in our study population, alkaline phosphatase had a higher level in the AAC group which presented CKD.

Aging, diabetes mellitus, oxidative stress and inflammation are responsible for enhanced vascular calcification [24]. Our reports indicate that AAC tended to occur in elder patients with a more advanced CKD, data consistent with results from previous studies.

Mönckeberg calcifications which are frequent in CKD patients can lead to coronary arteries calcification only in exceptional cases [34]. Previous studies reported the lack of a significant association between decreased kidney function and coronary artery calcification, however, AAC is associated with the presence of coronary artery calcification identified by spiral computed tomography in non-CKD patients $[35,36]$. We could not identify a difference in CAD prevalence between the evaluated groups, hence $A A C$ was not a risk factor for CAD.

Additionally, we found a positive but non-significant correlation between AAC and carotid stenosis which might be explained by the shifting of cholesterol levels in the AAC group.

\section{CONCLUSIONS}

Increased alkaline phosphatase remains an important risk factor for AAC even in patients with less advanced CKD. Lactate dehydrogenase is yet to be validated as a marker for AAC in CKD patients, however, our study reports a statistically significant association between lactate dehydrogenase and AAC. 


\section{REFERENCES}

1. Thompson $\mathrm{S}$, James $\mathrm{M}$, Wiebe $\mathrm{N}$ et al. Cause of Death in Patients with Reduced Kidney Function. J Am Soc Nephrol. 2015; 26:2504-2511.

2. Disthabanchong S. Vascular calcification in chronic kidney disease: Pathogenesis and clinical implication. World J Nephrol. 2012; 1:43-53.

3. Iribarren C, Sidney S, Sternfeld B, Browner WS. Calcification of the aortic arch: risk factors and association with coronary heart disease, stroke, and peripheral vascular disease. JAMA. 2000;283:2810-2815.

4. lijima $\mathrm{K}, \mathrm{Hashimoto} \mathrm{H}$, Hashimoto $M$ et al. Aortic arch calcification detectable on chest $X$-ray is a strong independent predictor of cardiovascular events beyond traditional risk factors. Atherosclerosis. 2010; 210:137-144.

5. Symeonidis G, Papanas N, Giannakis I et al. Gravity of aortic arch calcification as evaluated in adult Greek patients. Int Angiol. 2002;21:233-236.

6. Amann K. Media calcification and intima calcification are distinct entities in chronic kidney disease. Clin J Am Soc Nephrol. 2008;3:1599-1605.

7. Libby P, Ridker PM, Hansson GK. Progress and challenges in translating the biology of atherosclerosis. Nature. 2011;473:317-325.

8. Takasu J, Katz R, Nasir K et al. Relationships of thoracic aortic wall calcification to cardiovascular risk factors: the Multi-Ethnic Study of Atherosclerosis (MESA). Am Heart J. 2008;155:765-771.

9. Sage AP, Tintut Y, Demer LL. Regulatory mechanisms in vascular calcification. Nat Rev Cardiol. 2010;7:528-536.

10. Ehara S, Kobayashi Y, Yoshiyama M et al. Spotty calcification typifies the culprit plaque in patients with acute myocardial infarction: an intravascular ultrasound study. Circulation 2004;110:3424-3429.

11. Doherty TM, Asotra K, Fitzpatrick LA et al. Calcification in atherosclerosis: Bone biology and chronic inflammation at the arterial crossroads. Proc Natl Acad Sci USA. 2003;100:1201-1206.

12. Monckeberg JG. Uber die reine Mediaverkalkung der Exrtremittenarterien und ihr Verhalten zur Arteriosklerose. Virchows Arch Pathol Anat. 1903; 171:141-167.

13. Ballanti $P$, Silvestrini $G$, Pisanò $S$ et al. Medial artery calcification of uremic patients: A histological, histochemical and ultrastructural study. Histol Histopathol. 2011;26:191-200.

14. Abramowitz $\mathrm{Y}$, Jilaihawi $\mathrm{H}$, Chakravarty $\mathrm{T}$ et al. Porcelain aorta: A comprehensive review. Circulation. 2015;131:827-836.

15. Palit S, Kendrick J. Vascular calcification in chronic kidney disease: role of disordered mineral metabolism. Curr Pharm Des. 2014;20:5829-5833.

16. Schwarz U, Buzello M, Ritz E, et al. Morphology of coronary atherosclerotic lesions in patients with end-stage renal failure. Nephrol Dial Transplant. 2000; 15:218-223.

17. Schlaich MP, Socratous F, Hennebry S et al. Sympathetic activation in chronic renal failure. J Am Soc Nephrol. 2009;20:933939.

18. Guo J, Fujiyoshi A, Willcox B et al. Increased Aortic Calcification Is Associated With Arterial Stiffness Progression in Multiethnic Middle-Aged Men. Hypertension. 2017;69:102-108.

19. Jensky NE, Criqui MH, Wright MC et al. Blood pressure and vascular calcification. Hypertension. 2010;55:990-997.

20. Hashimoto $\mathrm{H} 1$, lijima K, Hashimoto $M$ et al. Validity and usefulness of aortic arch calcification in chest X-ray. J Atheroscler Thromb. 2009;16:256-264.

21. Williams B, Mancia G, Spiering W et al. 2018 ESC/ESH Guidelines for the management of arterial hypertension: The Task Force for the management of arterial hypertension of the European Society of Cardiology and the European Society of Hypertension: The Task Force for the management of arterial hypertension of the European Society of Cardiology and the European Society of Hypertension. J Hypertens. 2018;36:1953-2041.

22. Kidney Disease: Improving Global Outcomes (KDIGO) CKD Work Group. KDIGO. Clinical practice guideline for the evaluation and Management of Chronic Kidney Disease. Kidney Int Suppl. 2012;2013:1-150.

23. Hwang HS, Cho JS, Hong YA et al. Vascular calcification and left ventricular hypertrophy in hemodialysis patients: interrelationship and clinical impacts. Int J Med Sci. 2018; 15:557-563.

24. Nitta K, Ogawa T. Aortic arch calcification and clinical outcome in patients with end-stage renal disease. Tohoku J. Exp. Med. 2011;223:79-84
25. Kendrick J, Chonchol M. The role of phosphorus in the development and progression of vascular calcification. Am J Kidney Dis. 2011; 58:826-834.

26. Di Marco GS, König M, Stock $C$ et al. High phosphate directly affects endothelial function by downregulating annexin II. Kidney Int. 2013;83:213-222.

27. Sage AP, Lu J, Tintut Y, Demer LL. Hyperphosphatemia-induced nanocrystals upregulate the expression of bone morphogenetic protein-2 and osteopontin genes in mouse smooth muscle cells in vitro. Kidney Int. 2011;79:414-422.

28. Mclntyre CW. Calcium balance during hemodialysis. Semin Dial. 2008; 21:38-42.

29. Chen JH, Chuang SY, Chen HJ et al. Serum uric acid level as an independent risk factor for all-cause, cardiovascular, and ischemic stroke mortality: a Chinese cohort study. Arthritis Rheum. 2009;61:225-232.

30. Tanaka T, Hatakeyama S, Yamamoto $\mathrm{H}$ et al. Clinical relevance of aortic calcification in urolithiasis patients. BMC Urol. 2017; $17: 25$.

31. Kim H, Kim SH, Choi AR et al. Asymptomatic hyperuricemia is independently associated with coronary artery calcification in the absence of overt coronary artery disease: A single-center cross-sectional study. Medicine (Baltimore). 2017;96:e6565.

32. Kang SK, Ha CY, Cho KH et al. Changes of lactate dehydrogenase and its isoenzyme activity in renal diseases. Nephron. 1991; 57:55-59.

33. Shantouf R, Kovesdy CP, Kim Y et al. Association of serum alkaline phosphatase with coronary artery calcification in maintenance hemodialysis patients. Clin J Am Soc Nephrol. 2009;4:1106-1114.

34. Naha K, Shetty RK, Vivek G, Reddy S. Incidentally detected Monckeberg's sclerosis in a diabetic with coronary artery disease. BMJ Case Rep. 2012; 2012:bcr2012007376.

35. Ix JH, Katz R, Kestenbaum B et al. Association of mild to moderate kidney dysfunction and coronary calcification. J Am Soc Nephrol. 2008;19:579-585.

36. Adler Y, Fisman EZ, Shemesh J et al. Spiral computed tomography evidence of close correlation between coronary and thoracic aorta calcifications. Atherosclerosis. 2004; 176:133-138. 